\title{
miR-499 promotes immature porcine Sertoli cell growth through the PI3K/AKT pathway by targeting the PTEN gene
}

\author{
Hu Gao, Bin Chen, Hui Luo, Bo Weng, Xiangwei Tang, Yao Chen, Anqi Yang and Maoliang Ran \\ College of Animal Science and Technology, Hunan Provincial Key Laboratory for Genetic Improvement of Domestic \\ Animal, Hunan Agricultural University, Hunan, Changsha, China \\ Correspondence should be addressed to M Ran or B Chen; Email: ranmaoliang0903@126.com or chenbin7586@126.com
}

\begin{abstract}
Sertoli cells are indispensable for normal spermatogenesis, and increasing evidence has shown that miRNAs participate in the regulation of Sertoli cell growth. However, the functions and regulatory mechanisms of miRNAs in Sertoli cells of domestic animals have not been fully investigated. In the present study, we mainly investigated the regulatory roles of miR-499 in immature porcine Sertoli cells. The results showed that miR-499 was mainly located in the basement section of seminiferous tubules of prepubertal porcine testicular tissue. Overexpression of miR-499 promoted cell proliferation and inhibited apoptosis, whereas miR-499 inhibition resulted in the opposite effect. The PTEN gene was directly targeted by miR-499, and the expression of mRNA and protein was also negatively regulated by miR-499 in immature porcine Sertoli cells. siRNA-induced PTEN knockdown resulted in a similar effect as an overexpression of miR-499 and abolished the effects of miR-499 inhibition on immature porcine Sertoli cells. Moreover, both miR-499 overexpression and the PTEN knockdown activated the PI3K/AKT signaling pathway, whereas inhibition of the PI3K/AKT signaling pathway caused immature porcine Sertoli cell apoptosis and inhibited cell proliferation. Overall, miR-499 promotes proliferation and inhibits apoptosis in immature porcine Sertoli cells through the PI3K/AKT pathway by targeting the PTEN gene. This study provides novel insights into the effects of miR-499 in spermatogenesis through the regulation of immature Sertoli cell proliferation and apoptosis.

Reproduction (2020) 159 145-157
\end{abstract}

\section{Introduction}

Spermatogenesis is an intricate process containing three major phases including mitosis, meiosis, and spermiogenesis. This developmental process is precisely regulated to guarantee the generation of highly specialized spermatozoa. Sertoli cells, the sole somatic cells within the seminiferous tubules, play crucial regulatory roles in spermatogenesis. During the embryonic period, Sertoli cells prevent pro-spermatogonia from entering meiosis and promote Leydig cell differentiation. Then, they create a stable micro-environment for spermatozoa and secrete several functional proteins to regulate the multiple biological processes of generative cells during the adult period (Hai et al. 2014, Crisostomo et al. 2018, Griswold 2018). However, each Sertoli cell has a fixed capacity to support a number of developing germ cells, indicating that sperm production in the testis is governed by the number of Sertoli cells (Johnson et al. 2008, Rebourcet et al. 2017). In addition, immature Sertoli cells usually exhibit intense proliferation during the fetal to the prepubertal period, which ceases during the mature cell period (Sharpe et al. 2003). Hence, immature Sertoli cell proliferation is critical for spermatogenesis and male fertility.
miRNAs, a class of non-coding RNAs, widely participate in regulating multiple biological processes through binding the $3^{\prime}$ un-translated region (3'-UTR) of target genes and then causing translational inhibition. Specific deletion of the Sertoli cell-derived Dicer, a key enzyme in miRNA generation, severely impairs Sertoli cell maturation, function, and survival and further leads to infertility. This suggests that miRNAs in Sertoli cells are indispensable for normal spermatogenesis (Papaioannou et al. 2009). Recent years have witnessed the elucidation of the functions of several miRNAs in Sertoli cell proliferation and apoptosis, including miR762 (Ma et al. 2016b), miR-638 (Hu et al. 2017), miR1285 (Jiao et al. 2015), miR-196a (Zhang et al. 2019), miR-34c (Ran et al. 2019), miR-10b (Weng et al. 2019), and mi-26a (Ran et al. 2018a) in pigs; miR130a (Li et al. 2018b), miR-320-3p (Zhang et al. 2018), miR-17-92 cluster (Hurtado et al. 2018), and miR-2025p/3p (Wainwright et al. 2013) in mice; and miR-133b (Yao et al. 2016) and miR-202-3p (Yang et al. 2019) in humans, as well as miR-301b-3p/3584-5p (Yin et al. 2018 ) in rats. These abovementioned discoveries indicate that miRNAs are crucial epigenetic regulators in Sertoli cells. However, the functions and mechanisms of most 
identified miRNAs have not yet been fully elucidated (Ran et al. 2015, Weng et al. 2017b).

Our previous study found that miR-499 expression is significantly up-regulated during the embryonic and prepubertal periods compared to that during the adult period (Ran et al. 2015). This was further confirmed by another report indicating that miR-499 expression levels in porcine testicular tissues decreased quadratically with increasing age (Zhang et al. 2015). In addition, miR499 participates in regulating multiple cell biological processes, including cell proliferation (Li et al. 2016), apoptosis (Zhu et al. 2016), and differentiation (Jiang et al. 2018, Neshati et al. 2018). These clues suggest that miR-499 might play a regulatory role in the growth of immature porcine Sertoli cells, however, which mechanisms are involved remain unknown. The PTEN (phosphate and tension homology deleted on chromosome ten) gene, a key negative regulator of the phosphatidylinositide 3 kinases (PI3K)/AKT signaling pathway, has been predicted to be a direct target of miR499 (Ran et al. 2015, Weng et al. 2017b). Recent studies have demonstrated that PTEN or the PTEN-mediated PI3K/AKT signaling pathway are involved in Sertoli cell proliferation or apoptosis in rodents (Niu et al. 2015, Wang et al. 2015, 2017). We hypothesize that miR499 participates in the regulation of immature porcine Sertoli cell growth through the PI3K/AKT signaling pathway by targeting the PTEN gene. Therefore, the goal of the present study was to investigate the functions and potential molecular mechanisms of miR-499 in cell proliferation and apoptosis of immature porcine Sertoli cells.

\section{Materials and methods \\ Ethics statement}

This study was conducted according to the guidelines of the Declaration of Helsinki, and all procedures involving animals were approved by the Ethics Committee of the Hunan Agricultural University, China.

\section{Fluorescence in situ hybridization}

Fresh testicular tissues were obtained from 1-day-old Shaziling pigs (an indigenous Chinese pig breed) after being given general anesthesia (Zoletil 50, Virbac Co., France). The pig testicular tissues were immediately incubated with $4 \%$ paraformaldehyde. The $4-\mu \mathrm{m}$-thick sections were subjected to proteinase $\mathrm{K}$ digestion at $37^{\circ} \mathrm{C}$ for $30 \mathrm{~min}$ and then immersed three times in RNase-free water for 3 min each. A cy3-labeled miR-499 probe was designed and synthesized by RiboBio (Guangzhou, China). Hybridization was performed with the cy3-labeled miR-499 probe (final concentration, $25 \mathrm{nM}$ in the cells) using a fluorescent in situ hybridization kit (RiboBio, China) following the manufacturer's protocols. After washing three times with PBS, the nuclei were marked by staining with DAPI (50 ng/ml, Sigma) for $5 \mathrm{~min}$. The images were captured using a fluorescence microscope.

Reproduction (2020) 159 145-157

\section{Cell culture and transfection}

The commercial swine testis cells (ATCC ${ }^{\circledR}$ CRL-1746 ${ }^{\mathrm{TM}}$ ), isolated from swine 80- to 90-day-old fetal testes, have been identified as immature porcine Sertoli cells (Ma et al. 2016a). In addition, the marker genes of Sertoli cells including Sox9, $A m h$, and $W t 1$ are specifically expressed in the commercial swine testis cells (Ran et al. 2018b). The immature porcine Sertoli cells were cultured in Dulbecco's modified Eagle medium (HyClone, USA) containing 10\% fetal bovine serum (Gibco) at $37^{\circ} \mathrm{C}$ with $5 \% \mathrm{CO}_{2}$.

To measure the transfection efficiency of immature porcine Sertoli cells, $1.25 \mu \mathrm{L}$ of riboTRACER TM Fluorescent Oligo (final concentration, $50 \mathrm{nM}$ in the cells) (Ribobio, China) and $3 \mu \mathrm{L}$ of riboFECT TM CP Reagent (Ribobio, China) were diluted in $30 \mu \mathrm{L}$ of $1 \times$ riboFECT TM CP buffer (Ribobio, China) and incubated at room temperature for $15 \mathrm{~min}$. Then, this mixture was added in each well with $465.75 \mu \mathrm{L}$ of complete medium for $24 \mathrm{~h}$ when the cells clearly reached $80 \%$ confluence. We used a GE Healthcare IN Cell Analyzer to observe the cells. At least three independent biological replicates were used in this assay.

For cell transfection, $100 \mathrm{pmol}$ (final concentration, $50 \mathrm{nM}$ in the cells) miR-499 mimic (GenePharma, China), mimic negative control (mimic NC) (GenePharma, China), miR499 inhibitor (Ribobio, China), inhibitor NC (Ribobio, China), PTEN siRNA (Ribobio, China), siRNA NC (Ribobio, China), DMSO (Solarbio, China), LY294002 (PI3K inhibitor, dissolved in 0.5\% DMSO, MedChemExpress, USA), inhibitor $\mathrm{NC}+$ mimic NC, miR-499 inhibitor + siRNA NC, or miR-499 inhibitor + PTEN siRNA was diluted with $250 \mu \mathrm{L}$ of serum-free Opti-MEM (Thermo Fisher Scientific Inc.) and incubated at room temperature for $5 \mathrm{~min}$. Then, $5 \mu \mathrm{L}$ of Lipofectamine ${ }^{\mathrm{TM}}$ 2000 (Invitrogen) was also diluted with $250 \mu \mathrm{L}$ of serum-free Opti-MEM and incubated at room temperature for $5 \mathrm{~min}$. These two mixtures were mixed together and incubated at room temperature for $15 \mathrm{~min}$. Finally, the mixtures were added in each well when the cells reached approximately $80 \%$ confluence. After cultivation for $6-8 \mathrm{~h}$ at $37^{\circ} \mathrm{C}$ with $5 \% \mathrm{CO}_{2}$, the complete medium was used for cultivation. The sequence information is listed in Supplementary Table 1 (see section on supplementary materials given at the end of this article).

\section{Cell cycle assay}

The cell cycle was analyzed using a cell cycle testing kit(Nanjing KeyGen Biotech, China) according to the manufacturer's protocols. After a $24 \mathrm{~h}$ transfection, cells were washed three times using PBS and harvested in a $1.5-\mathrm{mL}$ centrifuge tube. Then, cells were incubated in $70 \%(\mathrm{v} / \mathrm{v})$ ethanol overnight at $-20^{\circ} \mathrm{C}$ and then in propidium iodide (PI) solution $(50 \mathrm{mg} /$ $\mathrm{mL}$ ) for $30 \mathrm{~min}$ at $4^{\circ} \mathrm{C}$. The cell suspension was analyzed on a FACSCanto II flow cytometer (Becton Dickinson, USA). Three independent replicates were conducted for each cell group.

\section{Cell proliferation assay}

Cell proliferation was examined using the cell counting kit-8 (CCK-8, Multiscience, China) and 5-ethynyl-2'-deoxyuridine (EdU, Ribobio, China) incorporation assays. Cells were seeded https://rep.bioscientifica.com 
in a 96-well culture plate at a density of $1 \times 10^{4}$ cells/well in $100 \mu \mathrm{L}$ of culture medium. For the CCK-8 assay, $10 \mu \mathrm{L}$ of CCK-8 medium was added in each well at $0 \mathrm{~h}$ or $48 \mathrm{~h}$ after transfection. Then, cells were incubated for $4 \mathrm{~h}$ at $37^{\circ} \mathrm{C}$. The absorbance value of each well was detected using an ELISA plate reader (Molecular Devices, USA) at $450 \mathrm{~nm}$. For the EdU assay, $100 \mu \mathrm{L}$ of EdU medium $(50 \mu \mathrm{mol})$ was added in each well $24 \mathrm{~h}$ after transfection, and cells were incubated for $2 \mathrm{~h}$ at $37^{\circ} \mathrm{C}$. Then, DNA staining solution and EdU staining solution were added in each well to mark living cells (blue) and the proliferating (red) cells according to the manufacturer's protocols, respectively. We used a fluorescence microscope to observe the cells at $20 \times$ and the ImageJ software to determine cell numbers. At least three independent biological replicates were used in these two assays.

\section{Cell apoptosis assay}

Cell apoptosis was detected using an Annexin V-FITC apoptosis detection kit (Nanjing KeyGen Biotech, China) and an ATP assay kit (Beyotime, China). Cells were cultured in 6-well plates with $2 \mathrm{~mL}$ medium. After a $24 \mathrm{~h}$ transfection, cells were collected in a 1.5-mL centrifuge tube. Before Annexin V-FITC apoptosis analysis, cells were washed three times and double stained with FITC-Annexin V and PI. Then, cell samples were analyzed using a FACSCanto II Flow Cytometer (Becton Dickinson, USA). Percentages of early apoptosis and late apoptosis cells were counted and used as the cell apoptosis rate. The ATP concentration was evaluated using an ATP assay kit (Beyotime, China) according to the manufacturer's protocols. The relative ATP level of experimental groups was normalized with the NC group. In addition, cell survival-related gene $(B C / 2, B A X$, and Caspase-3) protein expression levels were also measured using the Western blotting method.

\section{Dual-Iuciferase activity assay}

A target site between miR-499 and PTEN 3'UTR was predicted using TargetScan and RNAhybrid online software (Fig. 3A). A fragment of the PTEN 3'UTR harboring putative binding site of miR-499 was amplified using PTEN-3'UTR-W-F and PTEN-3'UTR-W-R primers (Supplementary Table 2). Then, a mutant PTEN 3'UTR with a six-base mutation at the putative binding site was also amplified using PTEN-3'UTR-Mut-F and PTEN-3'UTR-Mut-R primers (Supplementary Table 2). The abovementioned two fragments were subcloned into pmirGLO dual-luciferase vectors (Promega). The conducted vectors were co-transfected with miR-499 mimic or mimic NC into immature porcine Sertoli cells. After a $48 \mathrm{~h}$ transfection, we measured the luciferase activity of each cell group using the Dual-Glo luciferase assay system (Promega). Renilla luciferase (Promega) activity was used as the internal control.

\section{Real-time $q P C R$}

Real-time quantitative PCR (qPCR) was performed as in our previous studies (Ran et al. 2016, 2017, 2018b, Weng et al. 2017a). Total RNA was extracted using TRIzol reagent (Invitrogen) according to the manufacturer's protocols. The primers were designed using Oligo 7.0 software (Supplementary Table 2) and synthesized by Sango Bio. (Shanghai, China). The cDNA of each sample was synthesized using a Primescript first strand cDNA synthesis kit (TaKaRa, China) according to the manufacturer's protocols. The qPCR amplifications were performed on a Thermo Scientific PIKO REAL 96 real-time PCR system using a SYBR Green kit (TaKaRa, China). All qPCR reactions were performed in triplicate. U6 and pig-TBP genes were used as internal controls for miR-499 and protein-coding genes, respectively. The relative expression of each gene was evaluated using the $2^{-\Delta \Delta C t}$ method.

\section{Western blotting}

Total cellular protein was extracted using the radio immunoprecipitation assay (RIPA) lysis buffer (Beyotime, China). Then, the protein concentration was measured using a bicinchoninic acid protein assay kit (BCA) (Beyotime, China) according the manufacturer's protocols. The boiled protein samples were electrophoresed on 10\% SDS-polyacrylamide gels and then transferred onto a PVDF membrane (Beyotime, China). The membrane containing protein fractions was blocked with $5 \%$ non-fat milk for $2 \mathrm{~h}$ and incubated with primary antibodies overnight at $4^{\circ} \mathrm{C}$, including PTEN $(0.31$ $\mu \mathrm{g} / \mathrm{L}$, Proteintech Group, USA), Bcl2 (0.3 $\mu \mathrm{g} / \mathrm{L}$, Proteintech Group, USA), BAX (0.34 $\mu \mathrm{g} / \mathrm{L}$, Proteintech Group, USA),

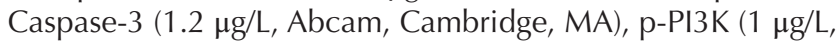
phospho Tyr458, Cell Signaling Technology, USA), p-AKT (1 $\mu \mathrm{g} / \mathrm{L}$, phospho Ser473, Affinity, USA), and $\beta$-actin $(1 \mu \mathrm{g} / \mathrm{L}$, Proteintech Group, USA). After washing, the membrane was incubated with secondary antibodies $(1 \mu \mathrm{g} / \mathrm{L}$, Proteintech Group, USA) for $2 \mathrm{~h}$ at room temperature. Protein bands were visualized using an ECL advanced Western blotting detection kit (Beyotime, China). $\beta$-actin served as the loading control.

\section{Statistical analysis}

Data are presented as the mean \pm S.D. Data from the experiment with multiple cell groups were subjected to a oneway ANOVA followed by Duncan's multiple comparison test of significance using SPSS 17.0 software. The $t$-test was used to test the differences in the experiment with only two cell groups. $P<0.05$ or $P<0.01$ was considered statistically significant.

\section{Results}

\section{Location of miR-499 in prepubertal porcine testicular tissue}

To identify the location of miR-499, we conducted a fluorescence in situ hybridization assay using fresh pig testicular tissues using 1-day-old samples. As shown in Fig. 1, the miR-499 was mainly located in the basement section of the seminiferous tubules where the Sertoli cells are usually located. This result suggested that miR-499 might play regulation roles in immature Sertoli cell growth because immature Sertoli cells usually exhibit intense proliferation during the prepubertal period. 

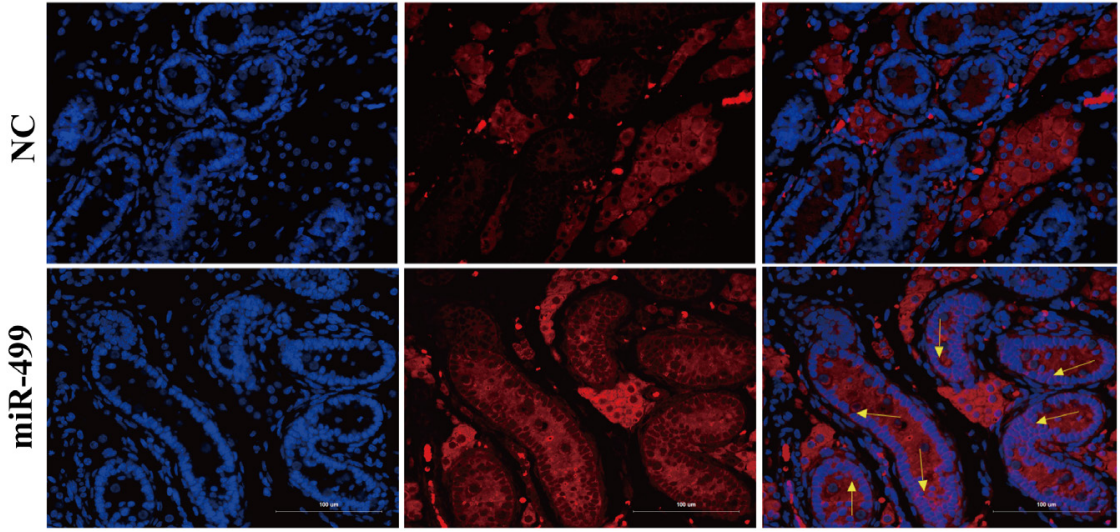

Figure 1 The location of miR-499 in prepubertal porcine testicular tissue. Testicular tissues of 1-day-old pigs were used in this experiment. Nuclei were marked by staining with DAPI (blue). The miR-499 was marked with red. Scale bar $=100 \mu \mathrm{m}$.

\section{miR-499 promotes immature porcine Sertoli cell proliferation}

The transfection efficiency of immature porcine Sertoli cells was measured through transfecting riboTRACER ${ }^{\text {TM }}$ Fluorescent Oligo and detected using a GE Healthcare IN Cell Analyzer. The results demonstrated that the green fluorescence signal was evenly detected in cells and that the transfection efficiency could reach 60-70\% (Supplementary Fig. 1A). In addition, the relative expression of miR-499 was significantly increased in the miR-499 transfected group (mimic NC, 1.013 \pm 0.206 ; miR-499 mimic, 1.862 \pm 0.396$)$, whereas significantly decreased in the miR-499 inhibitor group (inhibitor NC, $1.000 \pm 0.028$; miR-499 inhibitor, $0.578 \pm 0.029$ ) (Supplementary Fig. 1B).

The cell cycle analysis revealed that miR-499 overexpression increased the percentage of cells in the $S$ phase $(27.550 \pm 0.304 \%)$ compared with that in the mimic NC transfected cell group $(25.710 \pm 0.898 \%)$ (Fig. 2A and B). Conversely, fewer miR-499 inhibitor transfected cells were detected in the $S$ phase $(39.283 \pm 0.726 \%)$, whereas more cells were found in the G1 phase compared to that in the inhibitor NC transfection group $(41.990 \pm 0.443 \%)$ (Fig. 2A and C). Then, we further examined the relative expression levels of cell cycle-related genes $c-M Y C, C N N E 1, C C N D 1$, and $C D K 4$ in the abovementioned four cell groups. Expression levels of these four genes were up-regulated in the miR-499 mimic transfected cell group (C-

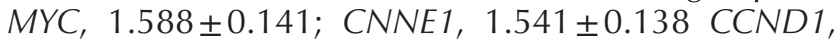
$1.541 \pm 0.139 ; C D K 4,2.341 \pm 0.201)$ (Fig. 2E), whereas they decreased in the miR-499 inhibitor transfected cell

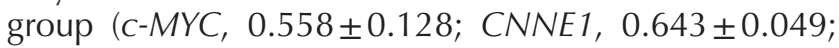
CCND1, 0.5125 $\pm 0.173 ; C D K 4,0.499 \pm 0.037$ ) (Fig. $2 \mathrm{~F})$. These results demonstrated that miR-499 promotes cell cycle progression.

Next, we further investigated the role of miR-499 in cell proliferation using the CCK-8 and EdU incorporation assays. The results from the CCK-8 assay revealed that miR-499 overexpression significantly increased the cell proliferation index from $3.571 \pm 0.070$ to $3.899 \pm 0.179$
$(P<0.05)$, whereas the miR-499 knockdown remarkably inhibited the proliferation index from 3.716 0.061 to $3.462 \pm 0.055(P<0.01)$ (Fig. 2D). Similarly, the EdU incorporation assay results indicated that miR-499 mimic transfected cells exhibited significantly higher mitotic activity (49.710 $\pm 1.845 \%$ of EdU-positive cells) than did the mimic NC transfected cells $(44.040 \pm 2.205 \%$ of EdUpositive cells) $(P<0.01)$, whereas the mitotic activity in the miR-499 inhibitor transfected cells was significantly inhibited $(53.270 \% \pm 1.338 \%$ to $50.420 \pm 1.232 \%$ of EdU-positive cells) $(P<0.01)$ (Fig. 2G and H). These results suggest that miR-499 promotes immature porcine Sertoli cell proliferation.

\section{miR-499 inhibits immature porcine Sertoli cell apoptosis}

It was shown that miR-499 promotes immature porcine Sertoli cell proliferation; thus, we determined whether miR-499 regulates cell apoptosis. The percentage of apoptosis in immature porcine Sertoli cell decreased from $3.316 \pm 0.210 \%$ to $2.653 \pm 0.311 \%$ after miR-499 upregulation and increased from $3.083 \pm 0.172 \%$ to $3.750 \pm 0.176 \%$ when miR-499 was knocked down (Fig. $3 \mathrm{~A}$ and $\mathrm{B})$. Cell growth is maintained by ATP; therefore, the ATP level can be used to access cell apoptosis (Li et al. 2018a). miR-499 overexpression resulted in an increase in the relative ATP level in immature porcine Sertoli cells (mimic NC, 1.000 \pm 0.017 ; miR499 mimic, $1.130 \pm 0.043)(P<0.01)$, whereas miR-499 knockdown decreased the relative ATP level (inhibitor NC, $1.000 \pm 0.032 ;$ miR-499 mimic, $0.880 \pm 0.013$ ) $(P<0.01)$ (Fig. 3C). The $\mathrm{Bcl} 2$ protein expression, an inhibitor of cell apoptosis, was markedly increased by mimic-induced miR-499 overexpression, whereas it was decreased by the miR-499 knockdown (Fig. 3D). Furthermore, overexpression and knockdown of miR-499, respectively, increased and decreased some apoptosis markers, including $\mathrm{Bcl} 2, \mathrm{BAX}$, and Caspase-3 protein expression (Fig. 3D). These results indicated that miR-499 inhibits immature porcine Sertoli cell apoptosis. 

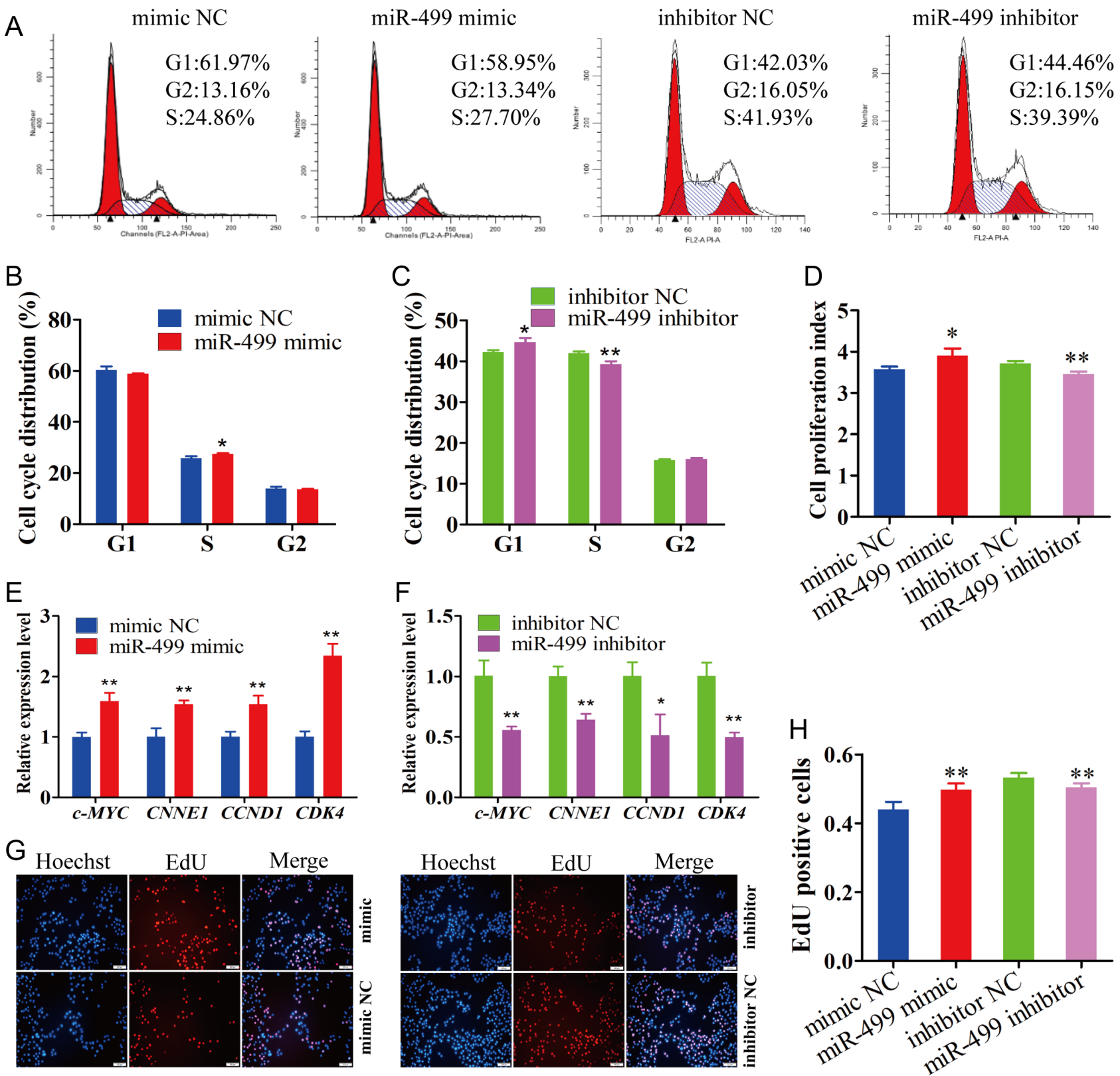

Figure 2 miR-499 promotes immature porcine Sertoli cell proliferation. The immature porcine Sertoli cells were transfected with mimic NC, miR-499 mimic, inhibitor NC, or miR-499 inhibitor. (A) Cell cycle was analyzed $24 \mathrm{~h}$ after transfection using a FACSCanto II flow cytometer. (B and C) The G1, S, and G2 phases of the cell cycle were counted in cells transfected with miR-499 mimic (B) or miR-499 inhibitor (C) ( $n=3)$. (D) The CCK-8 assay was used to measure the cell proliferation index $(n=3)$. (E and F) The mRNA relative expression of cell cycle-related genes C-MYC, CNNE1, CCND1, and CDK4 were detected in cells transfected with miR-499 mimic (E) or miR-499 inhibitor (F) using a qPCR assay $(n=3)$. The pig-TBP gene was used as the internal control. (G) Representative images of EdU staining of immature porcine Sertoli cells $24 \mathrm{~h}$ after transfection. Scale bar $=200 \mu \mathrm{m}$. (H) Results of the analysis of EdU-positive cells $(n=3)$. Data are presented as the mean \pm s.D. ${ }^{*} P<0.05$ and $* * P<0.01$.

\section{miR-499 activates the PI3K/AKT signaling pathway via targeting the PTEN gene}

To investigate the mechanism involved in the action of miR-499 on immature porcine Sertoli cell proliferation and apoptosis, we predicted the target genes of miR-499 using the TargetScan and RNAhybrid online software and found that the PTEN gene was a potential target gene
(Fig. 4A). Then, a fragment of the PTEN 3'UTR with the potential target site of miR-499 (wild type, W) or mutant nucleotides (mutant type, Mut) was subcloned into a psi-CHECK-2 dual-luciferase reporter vector. The $\mathrm{W}$ or Mut vector was co-transfected with the miR-499 mimic or mimic NC into immature porcine Sertoli cells. The ratio of luciferase activity was significantly suppressed 


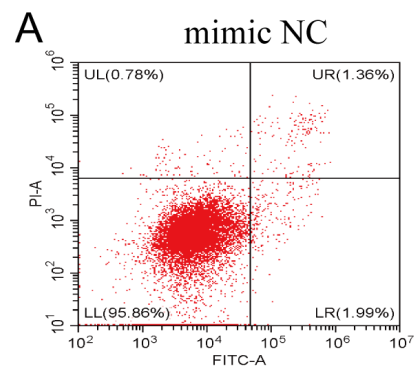

B

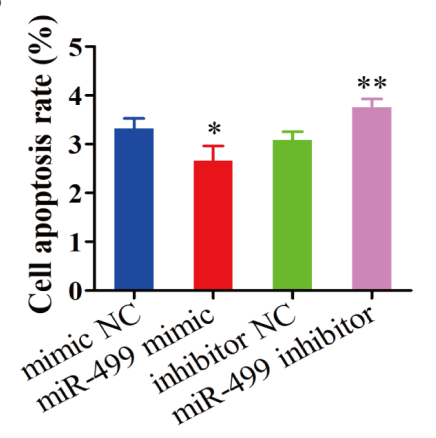

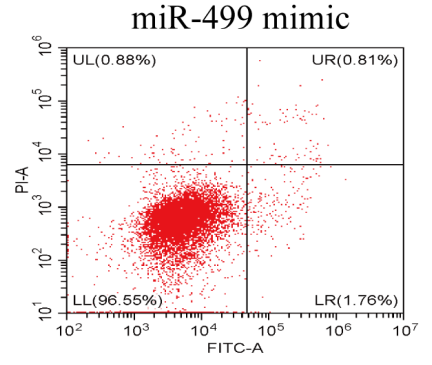

C

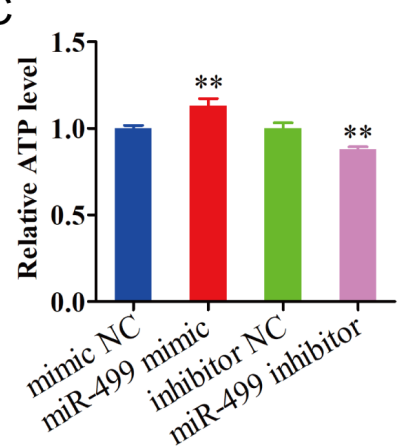

inhibitor NC

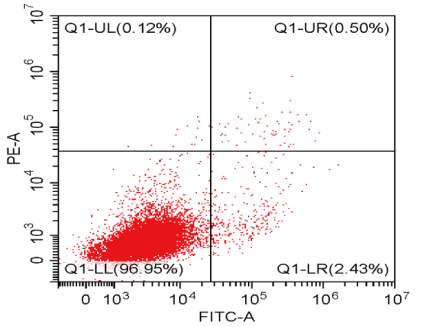

miR-499 inhibitor

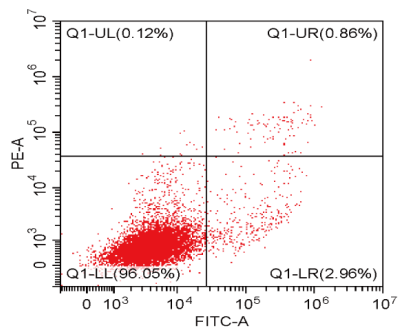

D

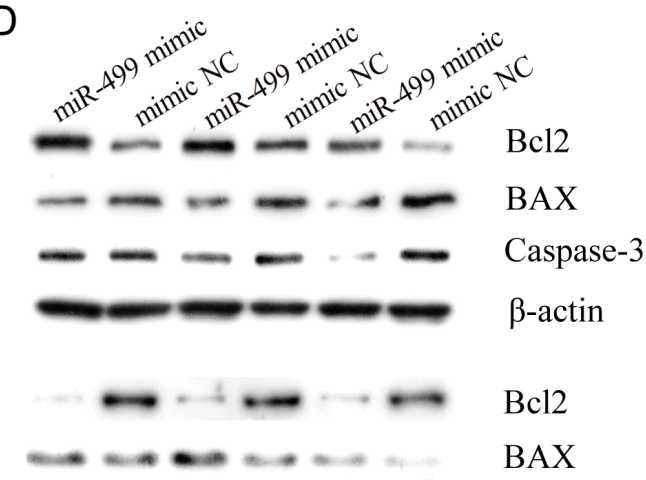

Caspase-3

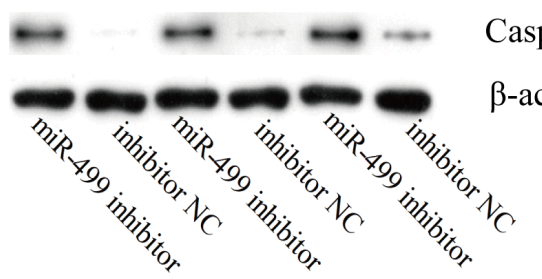

Figure 3 miR-499 inhibits immature porcine Sertoli cell apoptosis. The immature porcine Sertoli cells were transfected with mimic NC, miR-499 mimic, inhibitor NC, or miR-499 inhibitor. (A and B) Immature porcine Sertoli cell apoptosis phase distributions were checked (A) and counted (B) $24 \mathrm{~h}$ after transfection using Annexin V-FITC/PI staining assay $(n=3)$. (C) The relative ATP level was measured using an ATP assay kit. (D and E) The Western blot assay was used to detect the protein expression of cell apoptosis marker genes Bcl2, BAX, and Caspase-3 and key proteins in the PI3K/AKT signaling pathway (p-PI3K and p-AKT). The $\beta$-actin gene was used as the internal control. Data are presented as the mean \pm s.D. ${ }^{*} P<0.05$ and ${ }^{* *} P<0.01$.

A

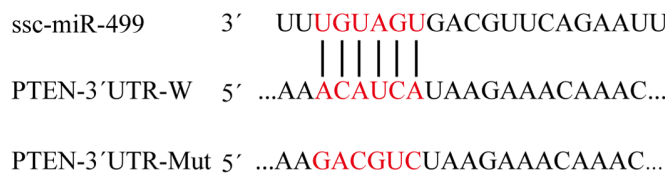

C

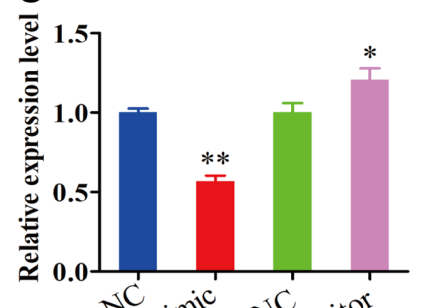

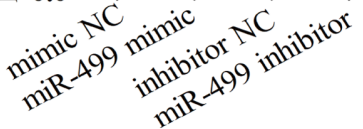

D

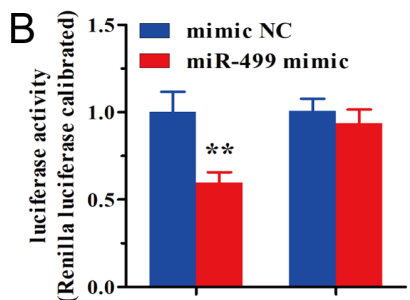

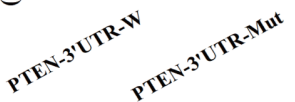

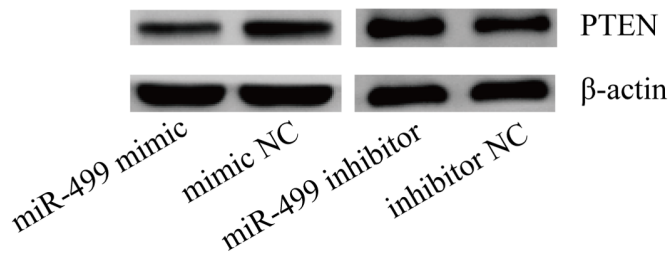

Figure 4 miR-499 directly targets the PTEN gene. (A) The PTEN gene was predicted as a target of miR-499 using the TargetScan and RNAhybrid online software. (B) Luciferase reporter assay results were quantified after co-transfection of the miR-499 mimic/mimic NC and PTEN-3'UTR-W/Mut vector into immature porcine Sertoli cells $(n=3)$. Renilla luciferase (Promega) activity was used as an internal control. (C and D) The PTEN mRNA (C) and protein expression (D) were measured using $\mathrm{qPCR}$ and Western blot assays, respectively $(n=3)$. The Pig-TBP and $\beta$-actin genes were used as internal controls in $\mathrm{QPCR}$ and Western blot assays, respectively. Data are presented as the mean \pm S.D. ${ }^{*} P<0.05$ and ${ }^{* *} P<0.01$. 
in cells co-transfected with the miR-499 mimic and the PTEN-3'UTR-W vector compared with that of other groups $(P<0.01)$ (Fig. 4B). In accordance with luciferase activity results, PTEN mRNA (mimic NC, $1.000 \pm 0.024$; miR-499 mimic, $0.569 \pm 0.035)$ and protein expressions were significantly down-regulated by miR-499 overexpression and up-regulated in response to the knockdown of miR-499 (inhibitor NC, $1.000 \pm 0.042$; miR-499 inhibitor, $1.138 \pm 0.021)(P<0.05)$ (Fig. 4C and D). These results demonstrated that miR-499 targets the PTEN gene and represses PTEN mRNA abundance in immature porcine Sertoli cells.
In previous studies, the PTEN gene was found to be a key negative regulator of the PI3K/AKT signaling pathway. Therefore, we further accessed whether the effect of miR-499 on activation of PI3K and AKT was dependent on the PTEN gene. Interestingly, overexpression of miR499 increased p-PI3K and p-AKT protein levels, whereas knockdown of miR-499 decreased these protein levels (Fig. 3E). In addition, the PTEN knockdown showed a similar effect with miR-499 overexpression (Fig. 5I). Considered together, we speculate that miR-499 activates the PI3K/AKT signaling pathway by targeting the PTEN gene in immature porcine Sertoli cells.
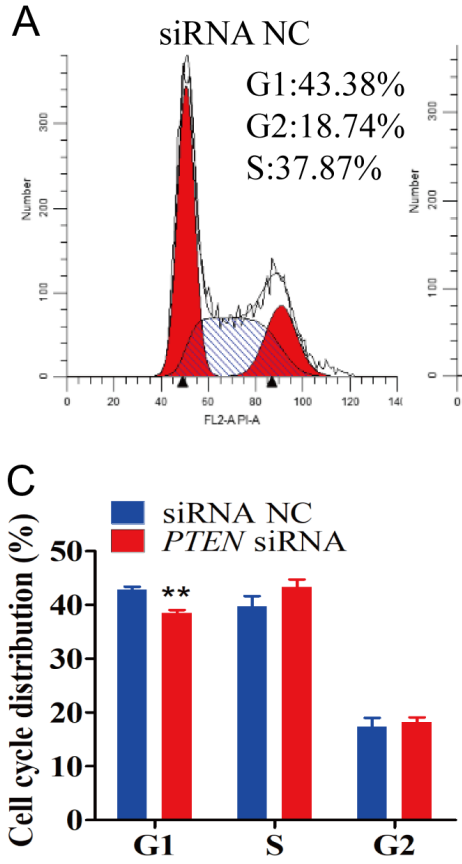

\section{PTEN SIRNA}
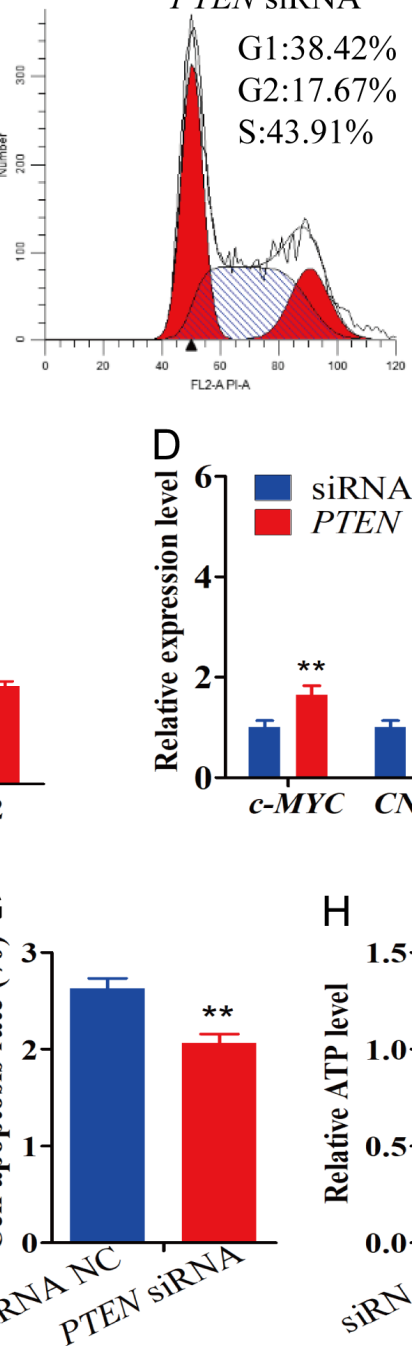

G

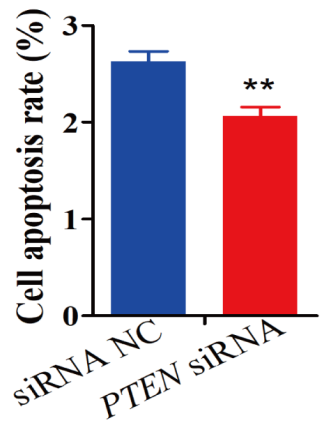

B SiRNA NC

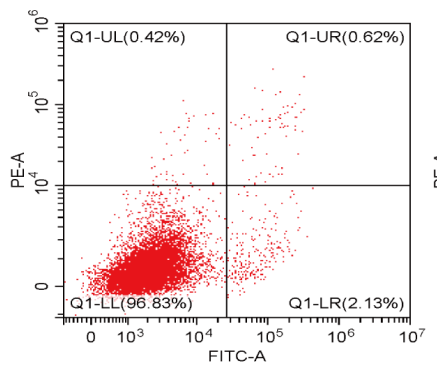

PTEN siRNA

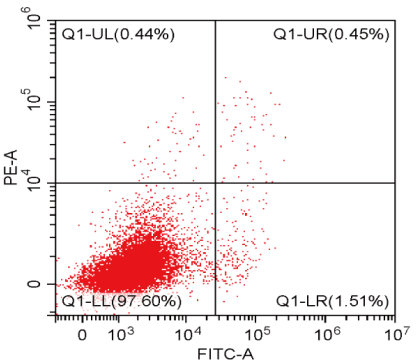

$\mathrm{F}$

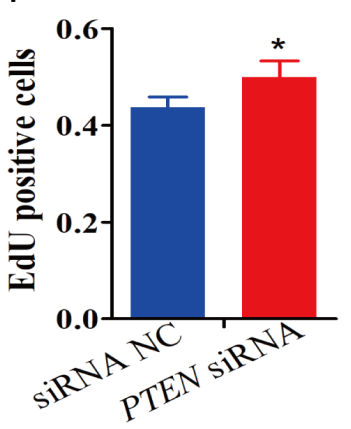

$\mathrm{H}$

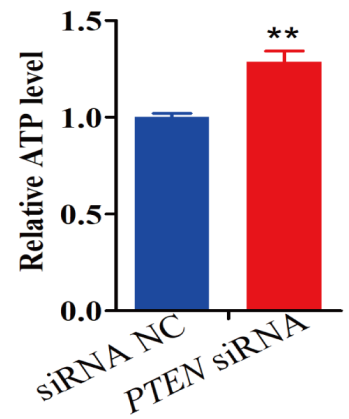

$\mathrm{E}$

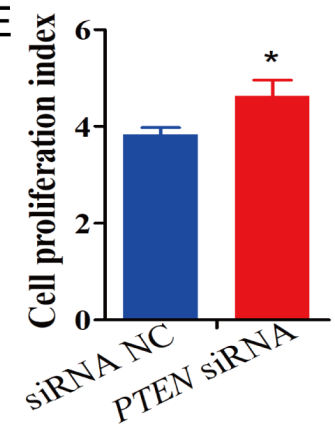

Figure 5 PTEN gene deficiency promotes immature porcine Sertoli cell proliferation and inhibits cell apoptosis. PTEN siRNA was transfected into immature porcine Sertoli cells to knockdown PTEN gene expression. (A and C) The cell cycle was detected (A) and counted (B) using a FACSCanto II Flow Cytometer $(n=3)$. (D) The mRNA relative expression of the cell cycle-related genes $c-M Y C$, CNNE1, $C C N D 1$, and CDK4 were detected using qPCR assay $(n=3)$. The pig-TBP gene was used as the internal control. (E and F) The cell proliferation index and mitotic activity were measured using CCK-8 (E) and EdU incorporation assay (F), respectively $(n=3)$. (B and G) Cell apoptosis rate was detected (B) and counted (G) using Annexin V-FITC/PI staining assay $(n=3)$. $(\mathrm{H})$ The relative ATP level was measured using an ATP assay kit. (I) The protein expression of Bcl2, BAX, Caspase-3, p-PI3K, and p-AKT were detected using Western blot assay. The $\beta$-actin gene was used as the internal control. Data are presented as the mean \pm s.D. ${ }^{*} P<0.05$ and $* * P<0.01$. 


\section{PTEN gene deficiency promotes immature porcine Sertoli cell proliferation and inhibits cell apoptosis}

We sought to determine whether the PTEN gene regulated immature porcine Sertoli cell proliferation and apoptosis. Cell cycle analysis indicated that siRNAinduced PTEN knockdown (Supplementary Fig. 1C) significantly decreased the percentage of cells in the G1 phase from $38.480 \pm 0.582 \%$ to $42.800 \pm 0.585 \%$ $(P<0.01)$ (Fig. 5A and $\mathrm{C}$ ). In addition, the expression of C-MYC (1.654 \pm 0.181$)$, CNNE1 (2.536 \pm 0.279$)$,

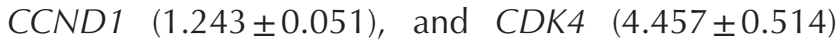
were significantly up-regulated in the PTEN siRNA transfected cell group compared with that of the siRNA $\mathrm{NC}$ transfected cell group (designated as 1.0) $(P<0.05)$ (Fig. 5D). The CCK-8 assay results showed that the PTEN knockdown promoted the cell proliferation index from $3.833 \pm 0.146$ to $4.633 \pm 0.322 \quad(P<0.05)$ (Fig. 5E). Similarly, the EdU incorporation assay results demonstrated that cell mitotic activity was significantly increased (from $43.690 \pm 2.18 \%$ to $49.990 \pm 3.345 \%$ of EdU-positive cells) by the knockdown of the PTEN gene $(P<0.05)$ (Fig. 5F).

Next, we clarified the roles of the PTEN gene on cell apoptosis. The Annexin V-FITC/PI staining assay revealed that the cell apoptosis rate was significantly repressed from $2.630 \pm 0.104 \%$ to $2.067 \pm 0.092 \%$ by the silencing of the PTEN gene $(P<0.01)$ (Fig. $5 \mathrm{~B}$ and $\mathrm{G})$. The knockdown of the PTEN gene significantly increased the relative ATP level from $1 \pm 0.02$ to $1.285 \pm 0.057$ in immature porcine Sertoli cells $(P<0.05)$ (Fig. $5 \mathrm{H})$. Furthermore, the Western blot assay indicated that $\mathrm{Bcl} 2$ protein expression was significantly increased, whereas BAX and Caspase-3 protein expression were significantly decreased by knocking down the PTEN gene (Fig. 5l). Overall, these data demonstrated that PTEN gene deficiency promotes immature porcine Sertoli cell proliferation and inhibits cell apoptosis.

\section{PTEN knockdown offsets the effects of miR- 499 inhibition}

Our results indicated that the PTEN gene knockdown resulted in similar results as those of the overexpression of miR-499 in cell proliferation and apoptosis. We then sought to determine whether the PTEN gene knockdown could reverse the roles of miR-499 in immature porcine Sertoli cells. Therefore, we constructed three co-transfection treatments including inhibitor $\mathrm{NC}+$ mimic NC, miR-499 inhibitor+siRNA NC, and miR-499 inhibitor+PTEN siRNA. Cell cycle results showed that the percentage of cells in the S phase was decreased from $49.840 \pm 2.192 \%$ to $45.603 \pm 1.469 \%$ in the miR-499 inhibitor + siRNA NC treatment $(P<0.05)$, whereas the miR-499 inhibitor + PTEN siRNA treatment increased cell percentage from $14.757 \pm 0.527 \%$ to $18.470 \pm 0.774 \%$ in the G2 phase $(P<0.05)$ (Fig. 6A).
The relative mRNA expression of CNNE1, CCND1, and CDK4 genes were significantly reduced by the miR499 inhibitor + siRNA NC treatment $(0.723 \pm 0.011$, $0.512 \pm 0.138,0.754 \pm 0.105)$ and increased by the miR499 inhibitor + PTEN siRNA treatment $(1.435 \pm 0.063$, $1.471 \pm 0.117,1.486 \pm 0.183) \quad(P<0.05) \quad$ compared with that of the inhibitor NC+ siRNA NC treatment (designated as 1.0) (Fig. 6B). Correspondingly, the CCK-8 and EdU incorporation assays showed that the PTEN knockdown could restrain the miR-499 inhibitorinduced lower proliferation activity of cells (Fig. 6C, D and E). In addition, the Annexin V-FITC/PI staining assay indicated that miR-499 inhibitor+siRNA NC caused a higher cell apoptosis rate $(3.620 \pm 0.600 \%)$ compared with that of the inhibitor NC+siRNA NC treatment $(2.637 \pm 0.108 \%) \quad(P<0.05)$, whereas this role was abolished by the PTEN knockdown $(2.593 \pm 0.240 \%)$ $(P<0.05)$ (Fig. 6F). Similarly, the protein expression of Bcl2 decreased significantly $(P<0.05)$, and the protein expression of BAX and Caspase- 3 increased in miR-499 inhibitor+siRNA NC co-transfected cells $(P<0.05)$, whereas these effects were attenuated by knocking down the expression of the PTEN gene (Fig. 6G). Collectively, these results indicated that the effects of miR-499 inhibition are attenuated by the PTEN knockdown.

\section{miR-499 promotes immature porcine Sertoli cell growth through activating the PI3K/AKT signaling pathway}

We have demonstrated that both miR-499 overexpression and PTEN knockdown activated the PI3K/AKT signaling pathway. Therefore, we sought to determine whether miR-499 regulates immature porcine Sertoli cell proliferation and apoptosis through activating the PI3K/AKT signaling pathway. Inhibition of PI3K/AKT signaling pathway arrested cells in the G1 phase, which was evidenced by more cells in the G1 phase (DMSO, $41.743 \pm 5.147 \%$; anti-PI3K/AKT, 54.256 $\pm 2.493 \%$ ) and fewer cells in the G2 phase (DMSO, $11.127 \pm 1.182 \%$; anti-PI3K/AKT, $4.340 \pm 3.891 \%$ ) (Fig. $7 \mathrm{~A}$ and C), as well as the down-regulation of the expression of cell cycle-related genes, including c-MYC $(0.346 \pm 0.178)$, CNN1 (0.089 \pm 0.037$), C C N D 1(0.370 \pm 0.210)$, and CDK4 (0.351 \pm 0.164$)$ (Fig. 7D). The CCK8 (DMSO, $3.682 \pm 0.103 ; \quad$ anti-PI3K/AKT, $4.706 \pm 0.116)$ and $\mathrm{EdU}$ incorporation assays (from $29.800 \pm 0.008 \%$ to $12.910 \pm 0.009 \%$ of EdU-positive cells) demonstrated that cell proliferation was inhibited after PI3K/AKT signaling pathway inhibition $(P<0.05)$ (Fig. $7 \mathrm{E}$ and $\mathrm{F})$. In addition, PI3K/AKT signaling pathway inhibition caused a higher cell apoptosis rate from $1.923 \pm 0.101 \%$ to $2.530 \pm 0.147 \%$ and a lower relative ATP level from $39.682 \pm 1.488$ to $33.509 \pm 1.781$ in immature porcine Sertoli cells (Fig. 7B, G and H). Correspondingly, the protein expression of $\mathrm{Bcl} 2$ decreased, and the protein expression of BAX and Caspase-3 increased in cells 

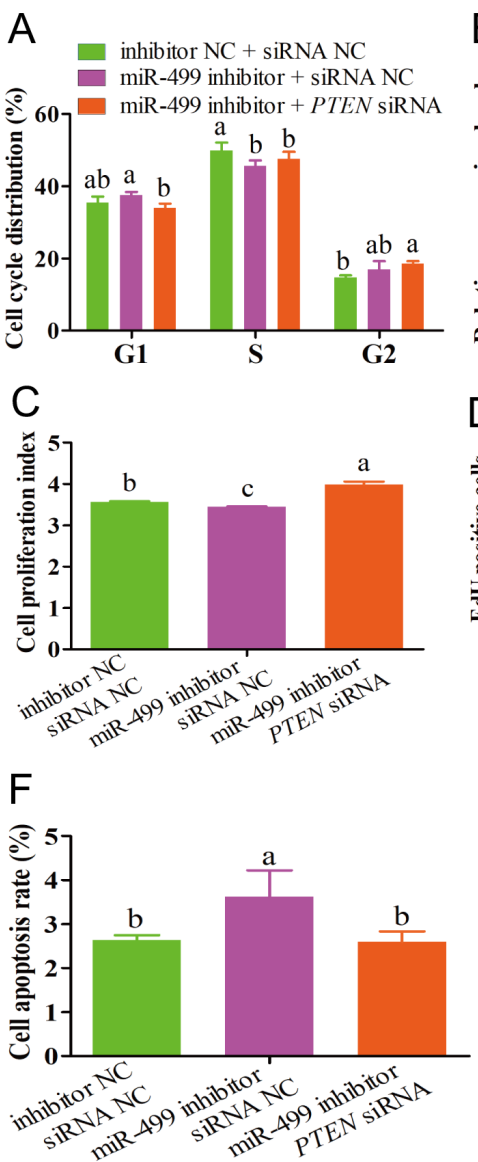
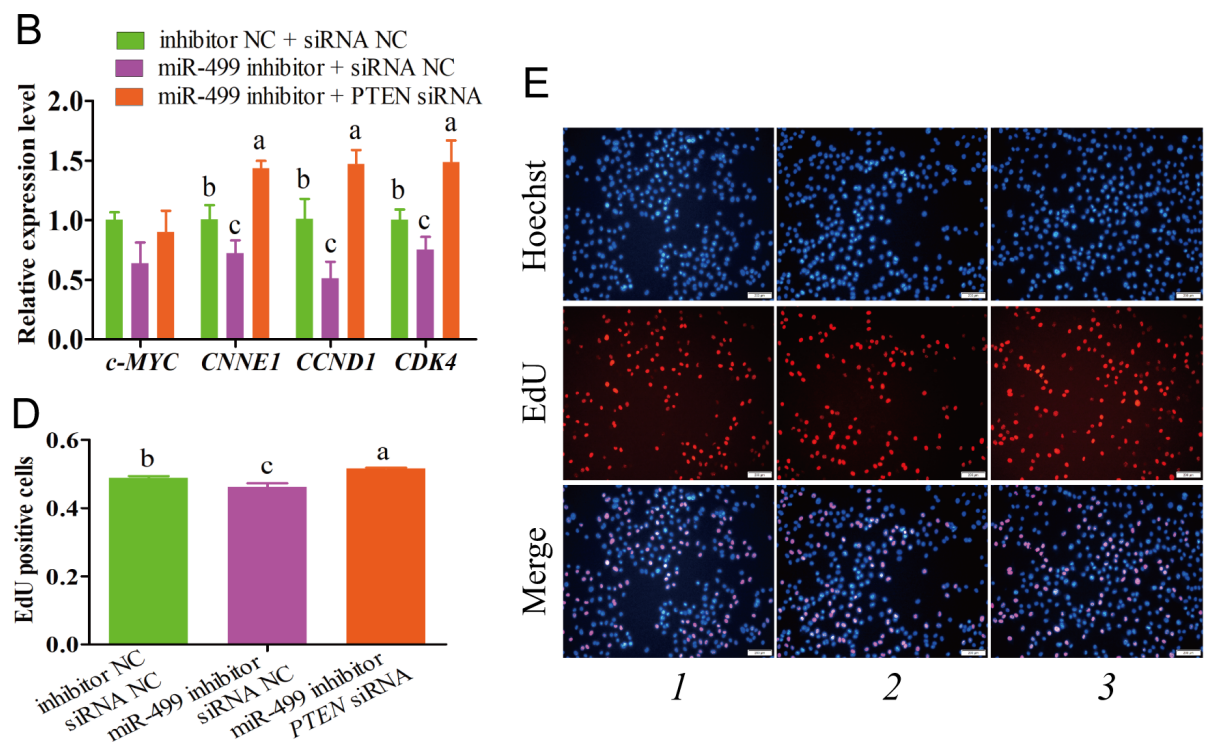

G

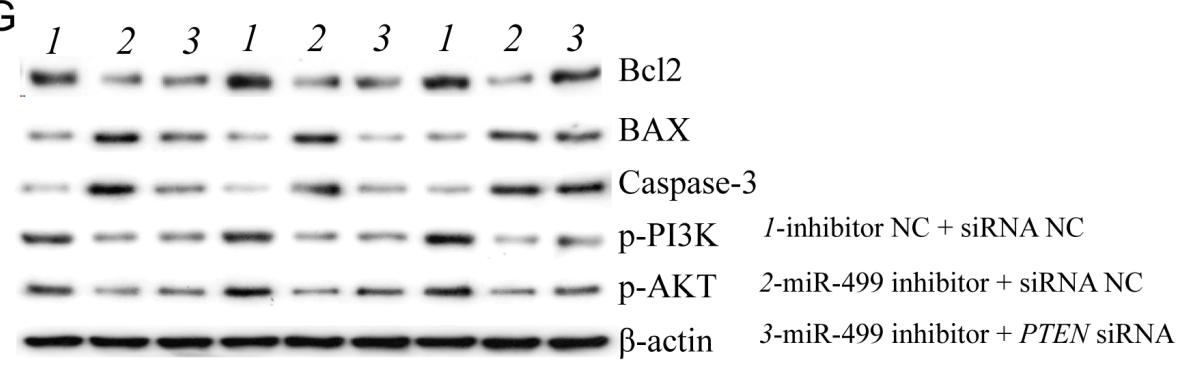

Figure 6 PTEN knockdown attenuates the effects of miR-499 inhibition in immature porcine Sertoli cells. Three co-transfection treatments including inhibitor NC+ mimic NC, miR-499 inhibitor + siRNA NC, and miR-499 inhibitor + PTEN siRNA were conducted in this section. (A) The cell cycle was detected and counted using a FACSCanto II flow cytometer $(n=3)$. (B) The mRNA relative expression of cell cycle-related genes C-MYC, CNNE1, CCND1, and CDK4 were detected using a GPCR assay $(n=3)$. The pig-TBP gene was used as the internal control. (C) The cell proliferation index was measured using the CCK-8 assay $(n=3)$. (D and E) Cell mitotic activity was measured (D) and counted (E) using the EdU incorporation assay $(n=3)$. (F) The cell apoptosis rate was detected and counted using the Annexin V-FITC/PI staining assay $(n=3)$. (G) The protein expression of Bcl2, BAX, Caspase-3, p-PI3K, and p-AKT were detected using a Western blot assay. The $\beta$-actin gene was used as the internal control. Data are presented as the mean \pm S.D. Different letters mean values within each section were significantly different.

with PI3K/AKT signaling pathway inhibition (Fig. 7I). Our results indicated that PI3K/AKT signaling pathway inhibition inhibited immature porcine Sertoli cell growth, which was opposite to that of miR-499 overexpression and PTEN knockdown.

\section{Discussion}

Sertoli cells are indispensable to guarantee the normal spermatogenesis process. Each Sertoli cell supports a limited number of germ cells, and the Sertoli cells lose proliferation capacity in the pubertal period. Therefore, the proliferation capacity of immature Sertoli cells determines the number of adult Sertoli cells in the pubertal period and further affects spermatogenesis. Most research on Sertoli cell proliferation and maturation focus on protein-coding genes (Griswold 2018), especially in domestic animals. More than 450 mature miRNAs have been identified from pigs, whereas regulatory roles and mechanisms of most identified miRNAs in Sertoli cells are not fully elucidated. In the present study, we report that miR-499 promotes immature porcine Sertoli cell growth through the PI3K/AKT pathway by targeting the PTEN gene.

Our previous study and that of others showed that miR-499 exhibits a higher expression level during the fetal and prepubertal periods than in the pubertal period in porcine testicular tissues (Ran et al. 2015, Zhang et al. 2015). It was further reported that miR-499 targets the QKI gene and represses its expression in immature porcine Sertoli cells (Zhang et al. 2015). Therefore, we speculated that miR-499 might play regulatory roles in immature porcine Sertoli cell growth. Recently, miR-499 has been reported to participate in cell proliferation, apoptosis, and differentiation in multiple cell types by targeting various genes, such as human tumor cells (i.e., SGC-7901, A-549, SW-480, and HepG-2s) (Long \& Pi 2018, Wan et al. 2018), mouse C2C12 and skeletal 

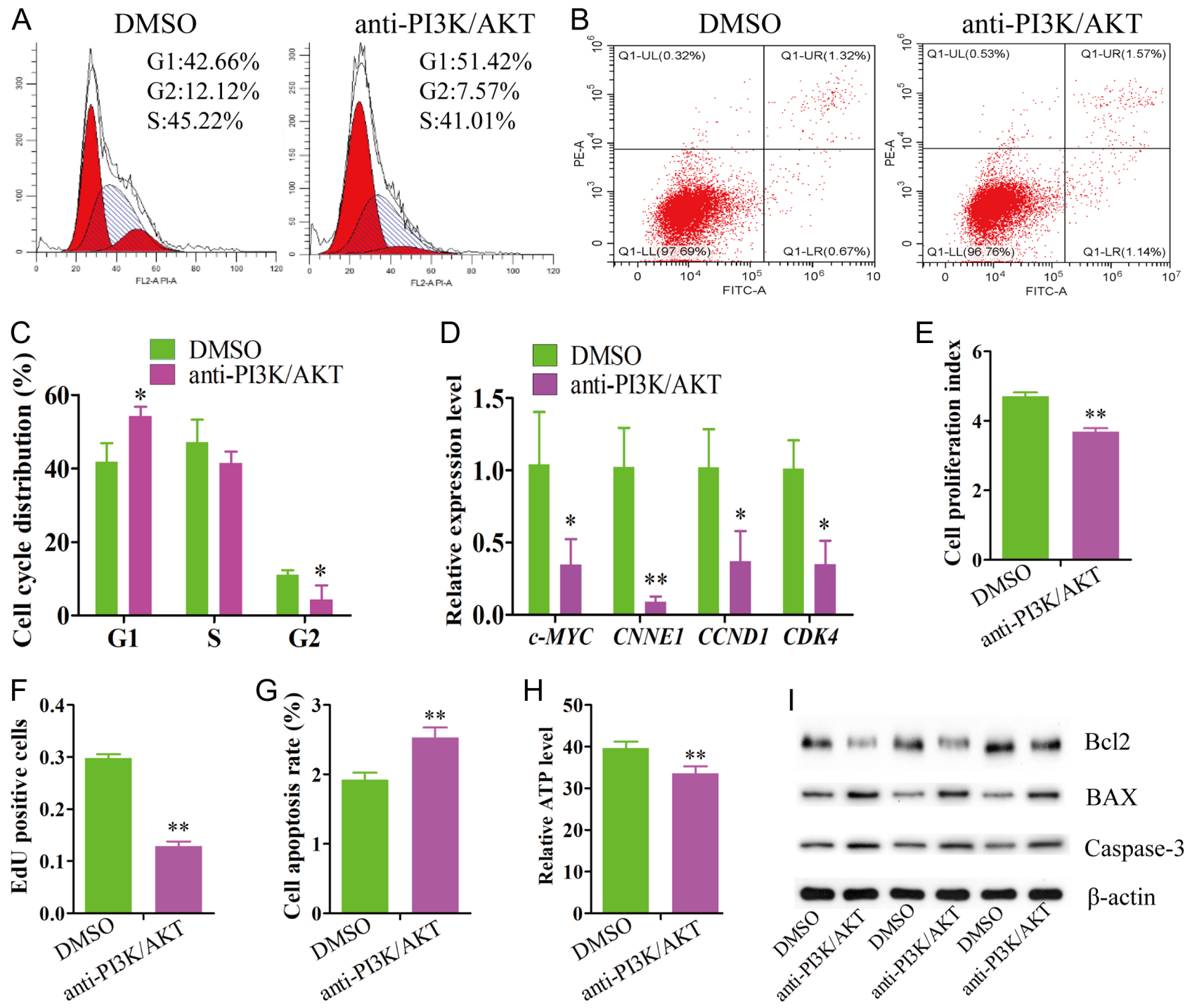

Figure 7 PI3K/AKT signaling pathway inactivation inhibits immature porcine Sertoli cell proliferation and promotes cell apoptosis. DMSO and LY294002 were added to the cell culture medium to function as NC and PI3K/AKT signaling pathway inactivation, respectively. (A and C) The cell cycle was detected (A) and counted (C) using a FACSCanto II flow cytometer $(n=3)$. (D) The mRNA relative expression of cell cycle-related genes C-MYC, CNNE1, CCND1, and CDK4 were detected using a qPCR assay $(n=3)$. The pig-TBP gene was used as the internal control. (E and F) The cell proliferation index and mitotic activity were measured using the CCK-8 (E) and EdU incorporation assays $(\mathrm{F})$, respectively $(n=3)$. $(B$ and G) Cell apoptosis rate was detected (B) and counted (G) using the Annexin V-FITC/PI staining assay $(n=3)$. (H) The relative ATP level was measured using an ATP assay kit. (I) The protein expression of Bcl2, BAX, Caspase-3, p-PI3K, and p-AKT were detected using a Western blot assay. The $\beta$-actin gene was used as the internal control. Data are presented as the mean \pm s.D. ${ }^{*} P<0.05$ and ${ }^{* *} P<0.01$.

muscle satellite cells (Jiang et al. 2018, Wu et al. 2019), and rat H9c2 cardiomyocytes (Ding et al. 2018). However, the regulatory roles of miR-499 in immature porcine Sertoli cells have not been elucidated. Our results illustrated that miR-499 overexpression promoted cell cycle progression, enhanced proliferation activity, decreased the cell apoptosis rate, and increased the relative ATP level in immature porcine Sertoli cells, whereas inhibition of miR-499 had an opposite effect.

In the present study, the PTEN gene was identified as a target of miR-499 using bioinformatics analysis and the luciferase assay, and the protein translation process of the
PTEN gene was also repressed by miR-499 in immature Sertoli cells. It has been shown that the PTEN gene is negatively regulated to immature mouse Sertoli cell proliferation, testis size, and sperm production in vivo (Neirijnck et al. 2019) and participates in bisphenol-A induced rat Sertoli cell apoptosis (Wang et al. 2015). In addition, various miRNAs promote proliferation and inhibit apoptosis by targeting the PTEN gene in several cell types (Li et al. 2018c), such as miR-374b in human gastrointestinal stromal tumor cells (Long et al. 2018), miR-524 and miR-93 in human osteosarcoma cells (Kawano et al. 2015, Zhuang et al. 2018), and miR-3142 
in chronic myeloid leukemia cells (Zhao et al. 2017). In the present study, siRNA-induced PTEN knockdown promoted proliferation and repressed apoptosis in immature porcine Sertoli cells, which was consistent with the effects of miR-499 overexpression. In addition, the effects of miR-499 inhibition were reversed by the PTEN knockdown. These results demonstrated that miR-499 promotes proliferation and inhibits apoptosis in immature porcine Sertoli cells through targeting the PTEN gene.

Phosphatidylinositol 3,4,5-trisphosphate (PIP3), a product of PI3K, is the key substrate of PTEN and the mediator of AKT (Matsuoka \& Ueda 2018). PTEN maintains PIP3 at a low expression level through dephosphorylating the PIP3. It has been widely established that the PTEN gene is a key negative regulator of the PI3K/AKT signaling in multiple processes, including cell progression, proliferation (Neirijnck et al. 2019), apoptosis, differentiation, migration, and autophagy (Wang et al. 2018). Several hormones participate in male Sertoli cell processes through regulating the PI3K/AKT signaling pathway. For example, thyroid hormone inhibits the proliferation of piglet Sertoli cells via the suppression of the PI3K/AKT signaling pathway (Sun et al. 2015). Follicle-stimulating hormone $(\mathrm{FSH})$ promotes the proliferation of immature rat Sertoli cells through the activation of the PI3K/AKT signaling pathway (Riera et al. 2012, Nascimento et al. 2016). 17 $\beta$-estradiol regulates immature boar Sertoli cell proliferation by activating the PI3K/AKT signaling pathway (Yang et al. 2017). Our results demonstrated that miR-499 overexpression inhibited PTEN mRNA and protein expression, and both miR-499 overexpression and PTEN knockdown increased the p-PI3K and p-AKT protein expression. These results showed that the miR499/PTEN/PI3K-AKT axis exists in immature porcine Sertoli cells, although its regulatory roles in immature porcine Sertoli cells remain unknown. Therefore, LY294002 was added into the cell medium to inhibit the activity of the PI3K/AKT signaling pathway. The results indicated that the inhibition of the PI3K/AKT signaling pathway repressed proliferation and promoted apoptosis in immature porcine Sertoli cells. These effects were similar to that of the miR-499 knockdown, whereas they were opposite to those of miR-499 overexpression and the PTEN knockdown.

In conclusion, this study proved that miR-499 promotes immature porcine Sertoli cell growth through the PI3K/AKT pathway by targeting the PTEN gene. We suspected that miR-499, PTEN, and the PI3K/AKT signaling pathway might play crucial regulatory roles in determining the fate of immature Sertoli cells.

\section{Supplementary materials}

This is linked to the online version of the paper at https://doi.org/10.1530/REP-19-0303.

\section{Declaration of interest}

The authors declare that there is no conflict of interest that could be perceived as prejudicing the impartiality of the research reported.

\section{Funding}

This work was financially supported by the Hunan Provincial Natural Science Foundation of China (2018JJ3219 and 2018JJ2176), a project supported by the scientific research fund of the Hunan Provincial Education Department (18B093), a science and technology project of Changsha City (kq1901032), and the earmarked fund for the China Agriculture Research System (CARS-36).

\section{Author contribution statement}

Ran $M L$ and Chen Bin contributed to experimental conception and design. Gao H, Ran M L, Luo H, Weng B, Tang X F, Chen $Y$, and Yang A Q performed the experiments. Ran M L and Gao $\mathrm{H}$ analyzed the data. Ran $\mathrm{ML}$ and Gao $\mathrm{H}$ wrote the first draft of the manuscript. All authors reviewed and approved the final manuscript.

\section{Acknowledgments}

The authors thank Guan Yang and Jie Yin for their critical reading of the manuscript.

\section{References}

Crisostomo L, Alves MG, Gorga A, Sousa M, Riera MF, Galardo MN, Meroni SB \& Oliveira PF 2018 Molecular mechanisms and signaling pathways involved in the nutritional support of spermatogenesis by Sertoli cells. Methods in Molecular Biology 1748 129-155. (https://doi. org/10.1007/978-1-4939-7698-0_11)

Ding W, Li M, Sun T, Han D, Guo X, Chen X, Wan Q, Zhang X \& Wang J 2018 A polymorphism rs3746444 within the pre-miR-499 alters the maturation of miR-499-5p and its antiapoptotic function. Journal of Cellular and Molecular Medicine 22 5418-5428. (https://doi. org/10.1111/jcmm.13813)

Griswold MD 201850 years of spermatogenesis: Sertoli cells and their interactions with germ cells. Biology of Reproduction 99 87-100. (https://doi.org/10.1093/biolre/ioy027)

Hai Y, Hou J, Liu Y, Liu Y, Yang H, Li Z \& He Z 2014 The roles and regulation of Sertoli cells in fate determinations of spermatogonial stem cells and spermatogenesis. Seminars in Cell and Developmental Biology 29 66-75. (https://doi.org/10.1016/j.semcdb.2014.04.007)

Hu P, Guan K, Feng Y, Ma C, Song H, Li Y, Xia X, Li J \& Li F 2017 miR-638 Inhibits immature Sertoli cell growth by indirectly inactivating PI3K/AKT pathway via SPAG1 gene. Cell Cycle 16 2290-2300. (https://doi.org/10. 1080/15384101.2017.1380130)

Hurtado A, Real FM, Palomino R, Carmona FD, Burgos M, Jimenez $\mathbf{R}$ \& Barrionuevo FJ 2018 Sertoli cell-specific ablation of miR-17-92 cluster significantly alters whole testis transcriptome without apparent phenotypic effects. PLOS ONE 13 e0197685. (https://doi.org/10.1371/ journal.pone.0197685)

Jiang J, Li P, Ling H, Xu Z, Yi B \& Zhu S 2018 MiR-499/PRDM16 axis modulates the adipogenic differentiation of mouse skeletal muscle satellite cells. Human Cell 31 282-291. (https://doi.org/10.1007/s13577018-0210-5)

Jiao ZJ, Yi W, Rong YW, Kee JD \& Zhong WX 2015 MicroRNA-1285 regulates 17 beta-estradiol-inhibited immature boar sertoli cell 
proliferation via adenosine monophosphate-activated protein kinase activation. Endocrinology 156 4059-4070. (https://doi.org/10.1210/ en.2014-1982)

Johnson L, Thompson Jr DL \& Varner DD 2008 Role of Sertoli cell number and function on regulation of spermatogenesis. Animal Reproduction Science 105 23-51. (https://doi.org/10.1016/j.anireprosci.2007.11.029)

Kawano M, Tanaka K, Itonaga I, Ikeda S, Iwasaki T \& Tsumura H 2015 microRNA-93 promotes cell proliferation via targeting of PTEN in Osteosarcoma cells. Journal of Experimental and Clinical Cancer Research 34 76. (https://doi.org/10.1186/s13046-015-0192-z)

Li M, Zhang S, Wu N, Wu L, Wang C \& Lin Y 2016 Overexpression of miR499-5p inhibits non-small cell lung cancer proliferation and metastasis by targeting VAV3. Scientific Reports 6 23100. (https://doi.org/10.1038/ srep23100)

Li B, Dou SX, Yuan JW, Liu YR, Li W, Ye F, Wang PY \& Li H 2018a Intracellular transport is accelerated in early apoptotic cells. PNAS $\mathbf{1 1 5}$ 12118-12123. (https://doi.org/10.1073/pnas.1810017115)

Li C, Yang B, Pan P, Ma Q, Wu Y, Zhang Z, Guo X, Ye J \& Gui Y $2018 b$ MicroRNA-130a inhibits spermatogenesis by directly targeting androgen receptor in mouse Sertoli cells. Molecular Reproduction and Development 85 768-777. (https://doi.org/10.1002/mrd.23058)

Li W, Zhang T, Guo L \& Huang L 2018c Regulation of PTEN expression by noncoding RNAs. Journal of Experimental and Clinical Cancer Research 37 223. (https://doi.org/10.1186/s13046-018-0898-9)

Long J \& Pi X 2018 IncRNA-MEG3 suppresses the proliferation and invasion of melanoma by regulating CYLD expression mediated by sponging miR-499-5p. BioMed Research International 20182086564. (https://doi.org/10.1155/2018/2086564)

Long ZW, Wu JH, Cai H, Wang YN \& Zhou Y 2018 MiR-374b promotes proliferation and inhibits apoptosis of human GIST cells by inhibiting PTEN through activation of the PI3K/Akt pathway. Molecules and Cells 41 532-544. (https://doi.org/10.14348/molcells.2018.2211)

Ma C, Song H, Guan K, Zhou J, Xia X \& Li F 2016a Characterization of swine testicular cell line as immature porcine Sertoli cell line. In Vitro Cellular and Developmental Biology: Animal 52 427-433. (https://doi. org/10.1007/s11626-015-9994-8)

Ma C, Song H, Yu L, Guan K, Hu P, Li Y, Xia X, Li J, Jiang S \& Li F 2016 b miR-762 promotes porcine immature Sertoli cell growth via the ring finger protein 4 (RNF4) gene. Scientific Reports 6 32783. (https://doi. org/10.1038/srep32783)

Matsuoka S \& Ueda M 2018 Mutual inhibition between PTEN and PIP3 generates bistability for polarity in motile cells. Nature Communications 9 4481. (https://doi.org/10.1038/s41467-018-06856-0)

Nascimento AR, Macheroni C, Lucas TF, Porto CS \& Lazari MF 2016 Crosstalk between FSH and relaxin at the end of the proliferative stage of rat Sertoli cells. Reproduction 152 613-628. (https://doi.org/10.1530/ REP-16-0330)

Neirijnck Y, Kuhne F, Mayere C, Pavlova E, Sararols P, Foti M, Atanassova N \& Nef S 2019 Tumor suppressor PTEN regulates negatively Sertoli cell proliferation, testis size, and sperm production in vivo. Endocrinology 160 387-398. (https://doi.org/10.1210/en.2018-00892)

Neshati V, Mollazadeh S, Fazly Bazzaz BS, de Vries AAF, Mojarrad M, Naderi-Meshkin H, Neshati Z, Mirahmadi M \& Kerachian MA 2018 MicroRNA-499a-5p promotes differentiation of human bone marrow-derived mesenchymal stem cells to cardiomyocytes. Applied Biochemistry and Biotechnology 186 245-255. (https://doi.org/10.1007/ s12010-018-2734-2)

Niu Z, Zheng L, Wu S, Mu H, Ma F, Song W, Zhu H, Wu J, He X \& Hua J 2015 Ras/ERK1/2 pathway regulates the self-renewal of dairy goat spermatogonia stem cells. Reproduction 149 445-452. (https://doi. org/10.1530/REP-14-0506)

Papaioannou MD, Pitetti JL, Ro S, Park C, Aubry F, Schaad O, Vejnar CE, Kuhne F, Descombes P, Zdobnov EM et al. 2009 Sertoli cell Dicer is essential for spermatogenesis in mice. Developmental Biology $\mathbf{3 2 6}$ 250-259. (https://doi.org/10.1016/j.ydbio.2008.11.011)

Ran ML, Chen B, Wu MS, Liu XC, He CQ, Yang AQ, Li Z, Xiang YJ, Li ZH \& Zhang SW 2015 Integrated analysis of miRNA and mRNA expression profiles in development of porcine testes. RSC Advances $\mathbf{5}$ 63439-63449. (https://doi.org/10.1039/C5RA07488F)

Ran M, Chen B, Li Z, Wu M, Liu X, He C, Zhang S \& Li Z 2016 Systematic identification of long noncoding RNAs in immature and mature porcine testes. Biology of Reproduction 94 77. (https://doi.org/10.1095/ biolreprod.115.136911)

Ran ML, Weng B, Chen B, Wu MS, He CQ \& Zhang SW 2017 Strand-specific RNA sequencing in pig testes identifies developmentally regulated genes and circular RNAs. Genes and Genomics 39 1083-1094. (https://doi. org/10.1007/s13258-017-0576-x)

Ran M, Li Z, Cao R, Weng B, Peng F, He C \& Chen B 2018a miR-26a suppresses autophagy in swine Sertoli cells by targeting ULK2. Reproduction in Domestic Animals 53 864-871. (https://doi.org/10.1111/ rda.13177)

Ran M, Weng B, Cao R, Li Z, Peng F, Luo H, Gao H \& Chen B 2018 b miR26 a inhibits proliferation and promotes apoptosis in porcine immature Sertoli cells by targeting the PAK2 gene. Reproduction in Domestic Animals 53 1375-1385. (https://doi.org/10.1111/rda.13254)

Ran ML, Weng B, Cao R, Peng FZ, Luo H, Gao H \& Chen B 2019 miR-34c inhibits proliferation and enhances apoptosis in immature porcine Sertoli cells by targeting the SMAD7 gene. Journal of Integrative Agriculture 18 449-459. (https://doi.org/10.1016/S2095-3119(19)62612-2)

Rebourcet D, Darbey A, Monteiro A, Soffientini U, Tsai YT, Handel I, Pitetti JL, Nef S, Smith LB \& O'Shaughnessy PJ 2017 Sertoli cell number defines and predicts germ and Leydig cell population sizes in the adult mouse testis. Endocrinology 158 2955-2969. (https://doi.org/10.1210/ en.2017-00196)

Riera MF, Regueira M, Galardo MN, Pellizzari EH, Meroni SB \& Cigorraga SB 2012 Signal transduction pathways in FSH regulation of rat Sertoli cell proliferation. American Journal of Physiology: Endocrinology and Metabolism $302 \quad$ E914-E923. (https://doi.org/10.1152/ ajpendo.00477.2011)

Sharpe RM, McKinnell C, Kivlin C \& Fisher JS 2003 Proliferation and functional maturation of Sertoli cells, and their relevance to disorders of testis function in adulthood. Reproduction 125 769-784. (https://doi. org/10.1530/rep.0.1250769)

Sun Y, Yang W, Luo H, Wang X, Chen Z, Zhang J, Wang Y \& Li X 2015 Thyroid hormone inhibits the proliferation of piglet Sertoli cell via PI3K signaling pathway. Theriogenology 83 86-94. (https://doi.org/10.1016/j. theriogenology.2014.08.003)

Wainwright EN, Jorgensen JS, Kim Y, Truong V, Bagheri-Fam S, Davidson T, Svingen T, Fernandez-Valverde SL, McClelland KS, Taft RJ et al. 2013 SOX9 regulates microRNA miR-202-5p/3p expression during mouse testis differentiation. Biology of Reproduction 89 34. (https://doi. org/10.1095/biolreprod.113.110155)

Wan Q, Xu T, Ding W, Zhang X, Ji X, Yu T, Yu W, Lin Z \& Wang J 2018 miR-499-5p attenuates mitochondrial fission and cell apoptosis via p21 in doxorubicin cardiotoxicity. Frontiers in Genetics 9 734. (https://doi. org/10.3389/fgene.2018.00734)

Wang C, Fu W, Quan C, Yan M, Liu C, Qi S \& Yang K 2015 The role of Pten/ Akt signaling pathway involved in BPA-induced apoptosis of rat Sertoli cells. Environmental Toxicology 30 793-802. (https://doi.org/10.1002/ tox.21958)

Wang H, Wang J, Zhang J, Jin S \& Li H 2017 Role of PI3K/AKT/mTOR signaling pathway in DBP-induced apoptosis of testicular Sertoli cells in vitro. Environmental Toxicology and Pharmacology 53 145-150. (https:// doi.org/10.1016/j.etap.2017.05.013)

Wang X, Li Y, Fan Y, Yu X, Mao X \& Jin F 2018 PTBP1 promotes the growth of breast cancer cells through the PTEN/Akt pathway and autophagy. Journal of Cellular Physiology 233 8930-8939. (https://doi.org/10.1002/ jcp.26823)

Weng B, Ran M, Chen B, He C, Dong L \& Peng F 2017 a Genome-wide analysis of long non-coding RNAs and their role in postnatal porcine testis development. Genomics 109 446-456. (https://doi.org/10.1016/j. ygeno.2017.07.001)

Weng B, Ran ML, Chen B, Wu MS, Peng FZ, Dong LH, He CQ, Zhang SW \& Li ZH 2017 b Systematic identification and characterization of miRNAs and piRNAs from porcine testes. Genes and Genomics 39 1047-1057. (https://doi.org/10.1007/s13258-017-0573-0)

Weng B, Ran ML, Cao R, Peng FZ, Luo H, Gao H, Tang XW, Yang AQ \& Chen B 2019 miR-10b promotes porcine immature Sertoli cell proliferation by targeting the DAZAP1 gene. Journal of Integrative Agriculture 18 1924-1935. (https://doi.org/10.1016/S2095-3119(19)62564-5)

Wu J, Yue B, Lan X, Wang Y, Fang X, Ma Y, Bai Y, Qi X, Zhang C \& Chen H 2019 MiR-499 regulates myoblast proliferation and differentiation by 
targeting transforming growth factor beta receptor 1. Journal of Cellular Physiology 234 2523-2536. (https://doi.org/10.1002/jcp.26903)

Yang WR, Zhu FW, Zhang JJ, Wang Y, Zhang JH, Lu C \& Wang XZ 2017 PI3K/Akt activated by GPR30 and Src regulates 17beta-estradiol-induced cultured immature boar Sertoli cells proliferation. Reproductive Sciences 24 57-66. (https://doi.org/10.1177/1933719116649696)

Yang C, Yao C, Tian R, Zhu Z, Zhao L, Li P, Chen H, Huang Y, Zhi E, Gong Y et al. 2019 miR-202-3p regulates Sertoli cell proliferation, synthesis function, and apoptosis by targeting LRP6 and cyclin D1 of Wnt/betacatenin signaling. Molecular Therapy: Nucleic Acids 14 1-19. (https:// doi.org/10.1016/j.omtn.2018.10.012)

Yao C, Sun M, Yuan Q, Niu M, Chen Z, Hou J, Wang H, Wen L, Liu Y, Li Z et al. 2016 MiRNA-133b promotes the proliferation of human Sertoli cells through targeting GLI3. Oncotarget 7 2201-2219. (https://doi. org/10.18632/oncotarget.6876)

Yin X, Ma T, Han R, Ding J, Zhang H, Han X \& Li D 2018 MiR-301b3p/3584-5p enhances low-dose mono-n-butyl phthalate (MBP)-induced proliferation by targeting Rasd1 in Sertoli cells. Toxicology in Vitro $\mathbf{4 7}$ 79-88. (https://doi.org/10.1016/j.tiv.2017.11.009)

Zhang X, Li C, Liu X, Lu C, Bai C, Zhao Z \& Sun B 2015 Differential expression of miR-499 and validation of predicted target genes in the testicular tissue of swine at different developmental stages. DNA and Cell Biology 34 464-469. (https://doi.org/10.1089/dna.2014.2728)

Zhang LL, Ma J, Yang B, Zhao J, Yan BY, Zhang YQ \& Li W 2018 Interference with lactate metabolism by mmu-miR-320-3p via negatively regulating GLUT3 signaling in mouse Sertoli cells. Cell Death and Disease 9964. (https://doi.org/10.1038/s41419-018-0958-2)
Zhang S, Guo J, Liang M, Qi J, Wang Z, Jian X, Zhang Z, Sun B \& Li Z 2019 miR-196a promotes proliferation and inhibits apoptosis of immature porcine Sertoli cells. DNA and Cell Biology 38 41-48. (https://doi. org/10.1089/dna.2018.4387)

Zhao L, Shan Y, Liu B, Li Y \& Jia L 2017 Functional screen analysis reveals miR-3142 as central regulator in chemoresistance and proliferation through activation of the PTEN-AKT pathway in CML. Cell Death and Disease 8 e2830. (https://doi.org/10.1038/cddis.2017.223)

Zhu J, Yao K, Wang Q, Guo J, Shi H, Ma L, Liu H, Gao W, Zou Y \& Ge J 2016 Ischemic postconditioning-regulated miR-499 protects the rat heart against ischemia/reperfusion injury by inhibiting apoptosis through PDCD4. Cellular Physiology and Biochemistry 39 2364-2380. (https:// doi.org/10.1159/000452506)

Zhuang M, Qiu X, Cheng D, Zhu C \& Chen L 2018 MicroRNA-524 promotes cell proliferation by down-regulating PTEN expression in osteosarcoma. Cancer Cell International 18 114. (https://doi.org/10.1186/s12935-0180612-1)

Received 16 July 2019

First decision 20 August 2019

Revised manuscript received 14 October 2019

Accepted 19 November 2019 